\title{
Adaptive neuro-fuzzy inference system based evolving fault locator for double circuit transmission lines
}

\author{
A Naresh Kumar, P Sridhar, T Anil Kumar, T Ravi Babu, V Chandra Jagan Mohan \\ Department of Electrical and Electronics Engineering, Institute of Aeronautical Engineering, Hyderabad, India
}

\begin{tabular}{l} 
Article Info \\
\hline Article history: \\
Received Dec 10, 2019 \\
Revised Feb 12, 2020 \\
Accepted Apr 4, 2020 \\
\hline
\end{tabular}

\section{Keywords:}

Detection time

Double circuit transmission line

Error

Evolving faults

Fault location

\begin{abstract}
Evolving faults are starting in one phase of circuit and spreading to other phases after some time. There has not been a suitable method for locating evolving faults in double circuit transmission line until now. In this paper, a novel method for locating different types of evolving faults occurring in double circuit transmission line is proposed by considering adaptive neuro-fuzzy inference system. The fundamental current and voltage magnitudes are specified as inputs to the proposed method. The simulation results using MATLAB verify the effectiveness and correctness of the protection method. Simulation results show the robustness of the method against different fault locations, resistances, time intervals, and all evolving fault types. Moreover, the proposed method yields satisfactory performance against percentage errors and fault location line parameters. The proposed method is easy to implement and cost-effective for new and existing double circuit transmission line installation.
\end{abstract}

This is an open access article under the $\underline{C C B Y-S A}$ license.

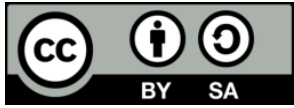

\section{Corresponding Author:}

A Naresh Kumar,

Department of Electrical and Electronics Engineering,

Institute of Aeronautical Engineering,

Hyderabad, 500043, Telangana, India.

Email: ankamnaresh29@gmail.com

\section{INTRODUCTION}

The growth of a country depends on availability of continuous electrical power supply. The power system consists of generating, transporting and utilizing electrical power. The only means of electrical power transmission is through transmission lines. Most of the transmission lines are overhead transmission lines which are open to the surrounding. Transmission lines are subject to different faults due to snow, storms, insulators breakdown, lightning, large birds and other external objects. Besides, when shunt fault takes place on transmission line in rural places, bushfire hazards may occur. Thus, detection of fault location within transmission line is crucial to minimize revenue loss, reduce unplanned outage time, improve network reliability and restore service rapidly. Many transmission line fault locating schemes based on soft computing techniques and double circuit transmission analysis have been introduced in the following literature work.

Most of the research work has been carried out for protection of double circuit three phase transmission lines (DCTPTL) [1-5]. The location of faults by considering fundamental component of currents and voltages in transmission line has been widely studied in Ref [6]. Further, different fault location algorithms have been presented in DCTPTL based on fuzzy inference system (FIS) [7-8], support vector machines [9], artificial neural networks (ANN) [10] and k-nearest neighbor algorithm [11]. Presence of a variety of individual computing methods [7-11] available for locating the DCTPTL is still having certain problems which limit their applicability. Hybridization of technologies can solve the 
limitations of individual computing applications. The adaptive neuro-fuzzy inference system (ANFIS) can be characterized as a hybrid' method, as it represents the integration of ANN and fuzzy logic technique. Recently, ANFIS has been found highly successful in applications such as evaluation of drought indices [12] and prediction of solar thermal energy system [13].

In the last few decades, ANFIS networks have been extensively used by researchers for location of transmission line faults [14-20]. Although, all the ANFIS location schemes [14-20] are designed to line to line faults (normal shunt faults) occurring at single time but are not applicable for line to line faults (evolving faults) occurring with time gap. Evolving faults include two sequential faults, resulting in the change of fault phase and time in DCTPTL. Some notable works have been reported in the literature on the location of evolving faults in transmission lines [21-27]. The complexity arising due to the time gap of two faults which adversely affect the performance of transmission line relaying. However, there is still a need to design fault location method to handle evolving faults. Hence, it can be concluded that, hitherto none of the earlier reported papers can locate evolving faults using ANFIS and DCTPTL current and voltage magnitudes.

In this regard, a novel method to locate evolving faults in the DCTPTL using ANFIS is presented in this paper. The novelty and highlights of the proposed work can be summarized as

1. Development of ANFIS based fault locator using single end fundamental current and voltage magnitudes and thus avoids the use of communication channel for sending and receiving terminals

2. Development of ANFIS without using classification method

3. Detects the evolving faults correctly

4. Further, another notable contribution of the proposed method is that it improves the accuracy of fault location and

5. Effectively distinguish the two successive faults different time positions on transmission lines.

The rest of this paper is structured as follows: Section 2 describes the DCTPTL simulation and training pattern generation. Section 3 presents the fault location algorithm for evolving faults using ANFIS. Section 4 reports the simulation results of fault location method. Section 5 provides conclusions.

\section{TRANSMISSION LINE SIMULATION AND TRAINING PATTERN GENERATION}

Figure 1 depicted the simplified diagram of the chosen $100 \mathrm{~km}, 400 \mathrm{kV}, 50 \mathrm{~Hz}$, DCTPTL. The MATLAB software is employed for DCTPTL and evolving faults simulation. DCTPTL is constructed using distributed parameter line block. Different evolving faults considered in this paper are 1 phase to ground fault changed to 2 phase to ground, 2 phase to ground faults changed to 3 phase to ground, 2 phase fault changed to 3 phase to ground fault and lastly 1 phase to ground fault changed to 2 phase to ground which again changed to 3 phase to ground.

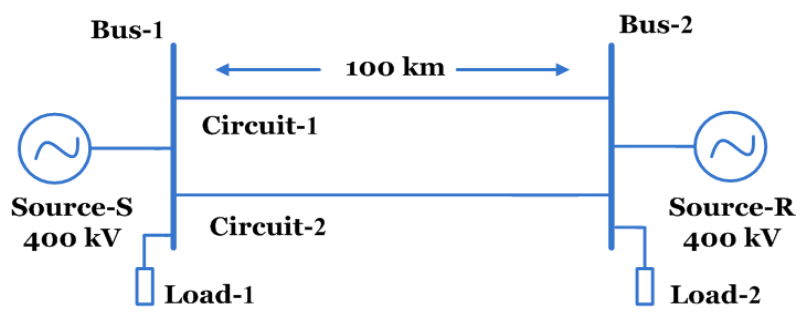

Figure 1 The simplified diagram of DCTPTL

The three phase current in circuit-1 IA1, IB1, IC1, and voltage VA, VB, VC waveforms of corresponding phases during an evolving fault in phase ' $\mathrm{A}$ ' at $72 \mathrm{~ms}$ time and phase ' $\mathrm{B}$ ' at $84 \mathrm{~ms}$ time at $80 \mathrm{~km}$ from the bus- 1 are exemplified in Figure 2 and Figure 3. 


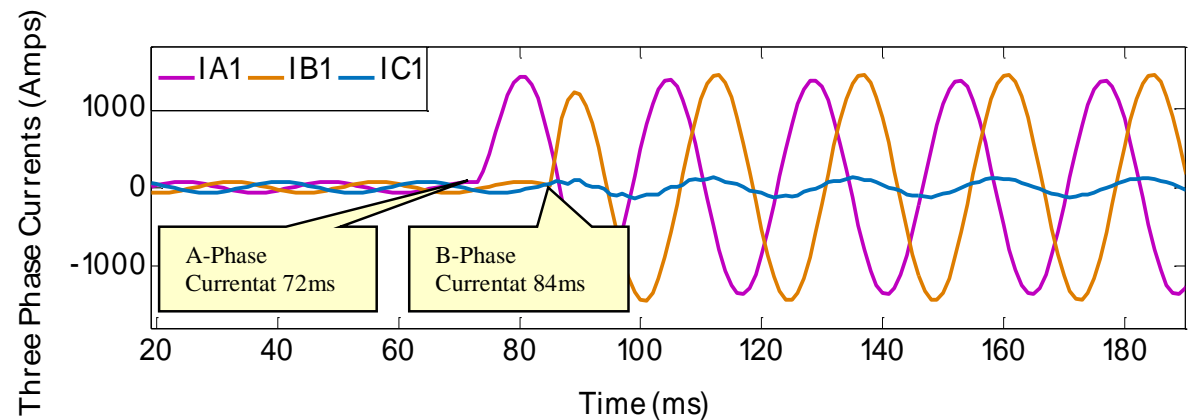

Figure 2. Current signals obtained during evolving faults

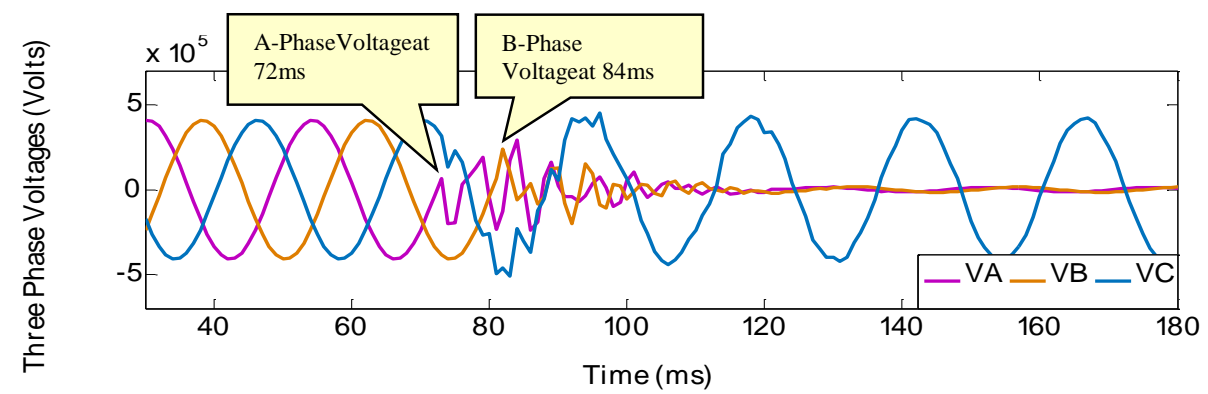

Figure 3. Voltage signals obtained during evolving faults

\section{PROPOSED METHOD}

The fuzzy and ANN have their own benefits and drawbacks. ANFIS has capability to capture the merits of both in a single construction. It is a type of adaptive network that is equivalent to FIS functionally. In this, to improve the accuracy of FIS model, neural network is used. The benefits of ANFIS are excellent explanation facilities through IF-Then rules, fast, easy to implement, accurate learning, easy to integrate both linguistic and numeric knowledge and strong generalization abilities. ANFIS can be adopted in a variety of applications of designing, signal processing, control and decision making. It can also be employed for both nonlinear and linear of input-output parameters.

For training of the ANFIS fault locator, various fault cases are simulated with change in evolving fault type, time interval, fault location and fault resistance. Three-phase voltages and currents in circuit- 1 and circuit-2 are collected from the source point for all fault cases. The fault parameters used for training of the ANFIS are listed in Table 1. It can be observed from the Table 1 that the number of fault cases for training is 1728. After simulating various fault cases with changing fault parameters, the voltage and current magnitudes measured at the source point are processed.

The ANFIS has constructed in MATLAB software with the DCTPTL simulation data. A single ANFIS has been developed to locate all types of evolving faults in both the circuits under different DCTPTL operating conditions. Nine inputs and single output are taken for developing ANFIS. The fundamental component of three phase current and voltage amplitudes are fed to ANFIS for locating the evolving faults. The fuzzy system inputs symbolize IA1f, IB1f, IC1f, IA2f, IB2f, IC2f, VAf, VBf and VCf. Its output symbolizes location of fault Lf. All input current values are classified as I1 to I5. Similarly, each voltage inputs are classified as V1 to V5 and output is classified as Lf1 to Lf5. The inputs and outputs are classified based on Gaussian membership functions. An array of five IF-Then rules is made for fuzzy system as explained below.

\section{IF-THEN Rules}

Rule-1:IF (IA1f is I5) or (IB1f is I5) or (IC1f is I5) or (IA2f is I5) or (IB2f is I5) or (IC2f is I5) or (VAf is V1) or (VBf is V1) or (VCf is V1) THEN (Lf is Lf1)

Rule-2:IF (IA1f is I4) or (IB1f is I4) or (IC1f is I4) or (IA2f is I4) or (IB2f is I4) or (IC2f is I4) or (VAf is $\mathrm{V} 2)$ or ( $\mathrm{VBf}$ is V2) or (VCf is V2) THEN ( $\mathrm{Lf}$ is Lf2) 
Rule-3:IF (IA1f is I3) or (IB1f is I3) or (IC1f is I3) or (IA2f is I3) or (IB2f is I3) or (IC2f is I3) or (VAf is V3) or (VBf is V3) or (VCf is V3) THEN (Lf is Lf3)

Rule-4:IF (IA1f is I2) or (IB1f is I2) or (IC1f is I2) or (IA2f is I2) or (IB2f is I2) or (IC2f is I2) or (VAf is V4) or (VBf is V4) or (VCf is V4) THEN (Lf is Lf4)

Rule-5:IF (IA1f is I1) or (IB1f is I1) or (IC1f is I1) or (IA2f is I1) or (IB2f is I1) or (IC2f is I1) or (VAf is V5) or (VBf is V5) or (VCf is V5) THEN (Lf is Lf5)

The fuzzy inference is computed by Takagi Sugeno model. The FIS and training data are given to the ANFIS. The ANN is training by back-propagation method. The most excellent performance is achieved by using back-propagation algorithm with 80 epochs, 5 Gaussian membership functions in each input and output with 5 IF then rules has been used. The structure of the developed ANFIS model is shown in Figure 4. In this way, ANFIS is developed, which provides only one output for location of evolving faults. Now ANFIS is ready to collect the current and voltage and can find the location of evolving faults. When the current and voltage magnitudes are given to the developed method, one of the aforementioned rules is fired and the corresponding location of evolving faults is obtained.

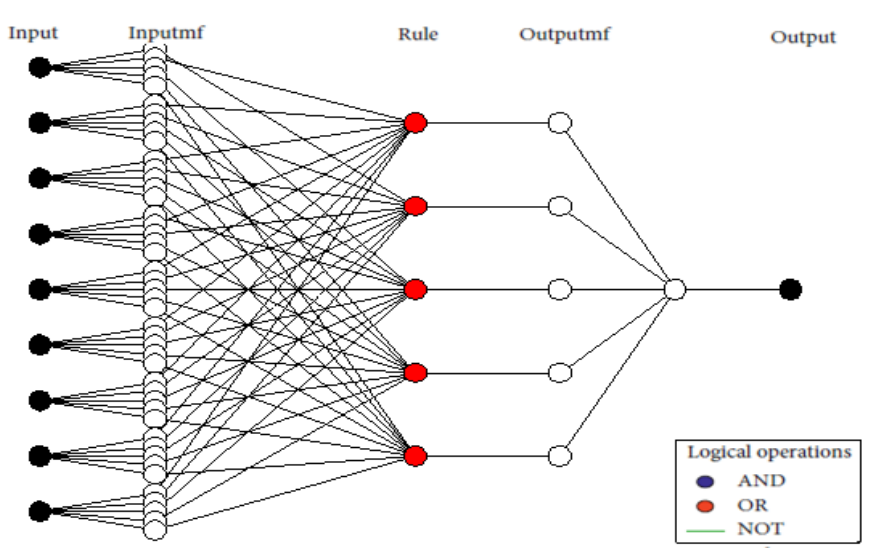

Figure 4. The structure of the developed ANFIS

Table 1. Training parameter changing

\begin{tabular}{|c|c|c|}
\hline Fault parameters & Training data & \\
\hline \multirow{4}{*}{$\begin{array}{c}\text { Fault type } \\
\text { (Evolving faults) } \\
{[24]}\end{array}$} & 1 phase to ground fault changed to 2 phase to ground fault & $\begin{array}{l}\text { A1-G to A1B1-G, } \\
\text { B1-G to B1C1-G, } \\
\text { C1-G toC1A1-G, } \\
\text { A2-G to A2B2-G, } \\
\text { B2-G to B2C2-G, } \\
\text { C2-G to C2A2-G. }\end{array}$ \\
\hline & 2 phase fault changed to 3 phase to ground fault & $\begin{array}{l}\mathrm{A} 1 \mathrm{~B} 1 \text { to } \mathrm{A} 1 \mathrm{BA} 1 \mathrm{C} 1-\mathrm{G}, \\
\mathrm{B} 1 \mathrm{C} 1 \text { to } \mathrm{A} 1 \mathrm{BA} 1 \mathrm{C} 1-\mathrm{G}, \\
\mathrm{C} 1 \mathrm{~A} 1 \text { to } \mathrm{A} 1 \mathrm{BA} 1 \mathrm{C} 1-\mathrm{G}, \\
\mathrm{A} 2 \mathrm{~B} 2 \text { to } \mathrm{A} 2 \mathrm{BA} 2 \mathrm{C} 2-\mathrm{G} \\
\mathrm{B} 2 \mathrm{C} 2 \text { to } \mathrm{A} 2 \mathrm{BA} 2 \mathrm{C} 2-\mathrm{G} \\
\mathrm{C} 2 \mathrm{~A} 2 \text { to } \mathrm{A} 2 \mathrm{BA} 2 \mathrm{C} 2-\mathrm{G} \text {. }\end{array}$ \\
\hline & 2 phase to ground faults changed to 3 phase to ground fault & $\begin{array}{l}\text { A1B1-G to A1BA1C1-G, } \\
\text { B1C1-G to A1BA1C1-G, } \\
\text { C1A1-G to A1BA1C1-G, } \\
\text { A2B2-G to A2BA2C2-G, } \\
\text { B2C2-G to A2BA2C2-G, } \\
\text { C2A2-G to A2BA2C2-G. }\end{array}$ \\
\hline & $\begin{array}{l}1 \text { phase to ground fault changed to } 2 \text { phase to ground which } \\
\text { again changed to } 3 \text { phase to ground fault }\end{array}$ & $\begin{array}{l}\text { A1-G to A1B1-G to A1B1C1-G, } \\
\text { B1-G to B1C1-G to A1B1C1-G, } \\
\text { C1-G to C1A1-G to A1B1C1-G, } \\
\text { A2-G to A2B2-G to A2B2C2-G, } \\
\text { B2-G to B2C2-G to A2B2C2-G, } \\
\text { C2-G to C2A2-G to A2B2C2-G. }\end{array}$ \\
\hline Fault location $(\mathrm{km})[12]$ & \multicolumn{2}{|c|}{$1,5,15,25,35,45,55,65,75,85,95,99$} \\
\hline Fault resistance $(\Omega)[2]$ & \multicolumn{2}{|c|}{0,100} \\
\hline Time interval (ms) [3] & \multicolumn{2}{|l|}{$10,20,30$} \\
\hline Total number cases & \multicolumn{2}{|l|}{$24 \times 12 \times 2 \times 3=1728$} \\
\hline
\end{tabular}




\section{RESULTS AND DISCUSSION}

The performance of the proposed ANFIS based fault location method has been examined and the results have been analyzed. In order to examine the response of proposed approach, it is necessary to get the relevant data which is never used during training process. Different parameters have been selected for checking the proposed ANFIS. Total 14000 test samples of evolving faults, with change in fault parameters like faults locations, fault resistances, fault types and time intervals have been collected. After the training process, the achieved optimal network configurations are checked with the MATLAB software tool samples. The error $(\%)$ in estimated fault location is calculated using (1). Some results of the evolving faults and proposed method are explained below.

$$
\text { Error }(\%)=\left|\frac{\text { Esitimated fault location }(\mathrm{km})-\text { Real fault location }(\mathrm{km})}{\text { Line length }}\right| \times 100
$$

\subsection{Performance changing evolving fault types}

In addition to ten types of shunts faults, DCTPTL is also prone to evolving faults due to animal/human and tree branch falling on live conductor normally begins off as single phase to ground faults. Most of the methods have been developed and unable to located especially evolving faults. Thus, the developed method is verified for different evolving faults in both the circuits of transmission lines. Performance changing evolving fault types, keeping invariable time interval (20 ms), constant resistance $(80 \Omega)$, and fixed location of fault $(65 \mathrm{~km})$ are listed in Table 2 . The error is up to $0.281 \%$ and detection time is up to $0.06 \mathrm{~ms}$ for all types of evolving fault. As seen in Table 2, evolving faults have no influence on the performance of the proposed method even for different evolving faults occurring in the line.

Table 2 Performance changing evolving fault types

\begin{tabular}{|c|c|c|c|c|c|c|c|}
\hline $\begin{array}{l}\text { Initial } \\
\text { Fault }\end{array}$ & $\begin{array}{l}\text { Evolving } \\
\text { Fault }\end{array}$ & $\begin{array}{c}\text { Time } \\
\text { Interval }(\mathrm{ms})\end{array}$ & $\begin{array}{c}\text { Fault Resistance } \\
(\Omega)\end{array}$ & $\begin{array}{l}\text { Fault Location } \\
(\mathrm{km})\end{array}$ & $\begin{array}{c}\text { Estimated } \\
\text { Location }(\mathrm{km})\end{array}$ & $\begin{array}{l}\text { Error } \\
(\%)\end{array}$ & $\begin{array}{l}\text { Detection Time } \\
(\mathrm{ms})\end{array}$ \\
\hline B1-G & $\mathrm{B} 1 \mathrm{C} 1-\mathrm{G}$ & 20 & 80 & 65 & 65.252 & 0.252 & 0.03 \\
\hline $\mathrm{A} 1 \mathrm{~B} 1$ & A1BA1C1-G & 20 & 80 & 65 & 65.201 & 0.201 & 0.06 \\
\hline $\mathrm{B} 1 \mathrm{C} 1$ & $\mathrm{~A} 1 \mathrm{BA} 1 \mathrm{C} 1-\mathrm{G}$ & 20 & 80 & 65 & 64.877 & 0.123 & 0.01 \\
\hline $\mathrm{C} 1 \mathrm{~A} 1$ & A1BA1C1-G & 20 & 80 & 65 & 65.011 & 0.011 & 0.04 \\
\hline C1A1-G & $\mathrm{A} 1 \mathrm{BA} 1 \mathrm{C} 1-\mathrm{G}$ & 20 & 80 & 65 & 65.160 & 0.160 & 0.04 \\
\hline A1-G & A1B1C1-G & 20 & 80 & 65 & 65.105 & 0.105 & 0.06 \\
\hline B1-G & A1B1C1-G & 20 & 80 & 65 & 64.841 & 0.159 & 0.04 \\
\hline $\mathrm{C} 1-\mathrm{G}$ & $\mathrm{A} 1 \mathrm{~B} 1 \mathrm{C} 1-\mathrm{G}$ & 20 & 80 & 65 & 65.063 & 0.063 & 0.04 \\
\hline A2-G & A2B2-G & 20 & 80 & 65 & 65.212 & 0.212 & 0.02 \\
\hline $\mathrm{C} 2 \mathrm{~A} 2$ & A2BA2C2-G & 20 & 80 & 65 & 65.098 & 0.098 & 0.06 \\
\hline A2B2-G & $\mathrm{A} 2 \mathrm{BA} 2 \mathrm{C} 2-\mathrm{G}$ & 20 & 80 & 65 & 65.281 & 0.281 & 0.04 \\
\hline B2C2-G & A2BA2C2-G & 20 & 80 & 65 & 65.025 & 0.085 & 0.02 \\
\hline $\mathrm{C} 2 \mathrm{~A} 2-\mathrm{G}$ & A2BA2C $2-G$ & 20 & 80 & 65 & 65.192 & 0.192 & 0.06 \\
\hline A2-G & $\mathrm{A} 2 \mathrm{~B} 2 \mathrm{C} 2-\mathrm{G}$ & 20 & 80 & 65 & 65.144 & 0.144 & 0.02 \\
\hline B2-G & $\mathrm{A} 2 \mathrm{~B} 2 \mathrm{C} 2-\mathrm{G}$ & 20 & 80 & 65 & 64.942 & 0.058 & 0.03 \\
\hline $\mathrm{C} 2-\mathrm{G}$ & $\mathrm{A} 2 \mathrm{~B} 2 \mathrm{C} 2-\mathrm{G}$ & 20 & 80 & 65 & 65.169 & 0.169 & 0.02 \\
\hline
\end{tabular}

\subsection{Performance changing time intervals}

The faults can take place with evolving fault type at any time; therefore, to study its effect on the developed method, a variety of time intervals for evolving faults have been applied. In order to explain the impact of time interval, the fault in the fixed location value $(43 \mathrm{~km})$ with constant resistance value $(50 \Omega)$ for the evolving fault type (A2-G to A2B2-G) and various time intervals has been considered. Some of results of fault location changing time intervals during evolving faults are illustrated in Table 3 . The error is up to $0.290 \%$ and detection time is up to $0.07 \mathrm{~ms}$ for all cases. The maximum error of the fault location in DCTPTL line remains acceptable regardless of the variation in the time intervals. 
Table 3 Performance changing time intervals

\begin{tabular}{ccccccc}
\hline $\begin{array}{c}\text { Initial } \\
\text { Fault }\end{array}$ & $\begin{array}{c}\text { Evolving } \\
\text { Fault }\end{array}$ & $\begin{array}{c}\text { Time } \\
\text { Interval }(\mathrm{ms})\end{array}$ & $\begin{array}{c}\text { Fault } \\
\text { Resistance }(\Omega)\end{array}$ & $\begin{array}{c}\text { Fault } \\
\text { Location }(\mathrm{km})\end{array}$ & $\begin{array}{c}\text { Estimated } \\
\text { Location }(\mathrm{km})\end{array}$ & $\begin{array}{c}\text { Error }(\%) \\
\text { Detection Time } \\
(\mathrm{ms})\end{array}$ \\
\hline A2-G & A2B2-G & 21 & 50 & 43 & 42.845 & 0.155 \\
A2-G & A2B2-G & 26 & 50 & 43 & 43.122 & 0.122 \\
A2-G & A2B2-G & 19 & 50 & 43 & 43.253 & 0.253 \\
A2-G & A2B2-G & 10 & 50 & 43 & 43.219 & 0.219 \\
A2-G & A2B2-G & 17 & 50 & 43 & 43.290 & 0.290 \\
A2-G & A2B2-G & 15 & 50 & 43 & 42.948 & 0.052 \\
A2-G & A2B2-G & 28 & 50 & 43 & 42.897 & 0.103 \\
A2-G & A2B2-G & 18 & 50 & 43 & 43.186 & 0.186 \\
A2-G & A2B2-G & 16 & 50 & 43 & 43.096 & 0.09 \\
A2-G & A2B2-G & 25 & 50 & 43 & 42.759 & 0.02 \\
A2-G & A2B2-G & 17 & 50 & 43 & 43.010 & 0.07 \\
A2-G & A2B2-G & 11 & 50 & 43 & 43.120 & 0.01 \\
\end{tabular}

\subsection{Performance changing fault resistance}

The fault resistance has a significant effect on the study of evolving fault analysis. Various fault resistances have been used in the simulation study and the results with typical fault resistances are reported here. To check its performance the evolving fault (A1B1-G to A1BA1C1-G), kept constant location (18km) and time interval $(15 \mathrm{~ms})$, and resistances are varied from $10 \Omega$ to $120 \Omega$. The test results of the developed method for evolving faults in DCTPTL under changing resistances are illustrated in Table 4. The error is up to $0.230 \%$ and detection time is up to $0.06 \mathrm{~ms}$ for all types of fault. Results give a satisfactory error of the proposed method for different fault resistances. What's more, the method stays unaffected by fault resistance. Even if the fault occurs on the vicinity of resistances, the method can locate evolving faults.

Table 4. Performance changing fault resistance

\begin{tabular}{|c|c|c|c|c|c|c|c|}
\hline $\begin{array}{l}\text { Initial } \\
\text { Fault }\end{array}$ & Evolving Fault & $\begin{array}{c}\text { Time } \\
\text { Interval (ms) }\end{array}$ & $\begin{array}{c}\text { Fault Resistance } \\
(\Omega)\end{array}$ & $\begin{array}{c}\text { Fault } \\
\text { Location }(\mathrm{km})\end{array}$ & $\begin{array}{c}\text { Estimated } \\
\text { Location }(\mathrm{km})\end{array}$ & $\begin{array}{c}\text { Error } \\
(\%)\end{array}$ & $\begin{array}{l}\text { Detection Time } \\
(\mathrm{ms})\end{array}$ \\
\hline A1B1-G & A1BA1C1-G & 15 & 5 & 18 & 18.078 & 0.078 & 0.03 \\
\hline A1B1-G & A1BA1C1-G & 15 & 10 & 18 & 18.056 & 0.056 & 0.04 \\
\hline A1B1-G & A1BA1C1-G & 15 & 20 & 18 & 17.770 & 0.230 & 0.05 \\
\hline A1B $1-G$ & A1BA1C1-G & 15 & 20 & 18 & 18.198 & 0.198 & 0.03 \\
\hline A1B1-G & A1BA1C1-G & 15 & 40 & 18 & 18.206 & 0.206 & 0.02 \\
\hline A1B1-G & A1BA1C1-G & 15 & 50 & 18 & 18.135 & 0.135 & 0.02 \\
\hline A1B1-G & A1BA1C1-G & 15 & 60 & 18 & 17.821 & 0.179 & 0.05 \\
\hline A1B1-G & A1BA1C1-G & 15 & 70 & 18 & 17.838 & 0.162 & 0.03 \\
\hline A1B1-G & A1BA1C1-G & 15 & 80 & 18 & 18.047 & 0.047 & 0.04 \\
\hline A1B1-G & A1BA1C1-G & 15 & 90 & 18 & 18.228 & 0.228 & 0.06 \\
\hline A1B1-G & A1BA1C1-G & 15 & 95 & 18 & 17.946 & 0.054 & 0.01 \\
\hline A1B1-G & A1BA1C1-G & 15 & 99 & 18 & 18.101 & 0.101 & 0.02 \\
\hline
\end{tabular}

\subsection{Performance changing fault location}

In this part, the simulation results with different fault locations are presented. The developed method is tested by keeping fixed time interval $(10 \mathrm{~ms})$, constant resistances $(20 \Omega)$, different locations of evolving fault (B1-G to B1C1-G) from the relaying point ranging from $\mathrm{Lf}=1 \mathrm{~km}$ to $99 \mathrm{~km}$ of the line. Some of the results of evolving faults in DCTPTL under changing locations are given in Table 5. The maximum absolute error percentage was $0.292 \%$ under evolving faults and maximum detection time taken by the proposed method is $0.06 \mathrm{~ms}$. As can be seen in Tables 5 the developed method is able to achieve a reasonably high accuracy in locating fault. Also, the performance of the developed method is not affected by variations in the fault location. 
Table 5 Performance changing fault location

\begin{tabular}{|c|c|c|c|c|c|c|c|}
\hline $\begin{array}{l}\text { Initial } \\
\text { Fault }\end{array}$ & $\begin{array}{l}\text { Evolving } \\
\text { Fault }\end{array}$ & $\begin{array}{c}\text { Time } \\
\text { Interval (ms) }\end{array}$ & $\begin{array}{c}\text { Fault Resistance } \\
(\Omega)\end{array}$ & $\begin{array}{c}\text { Fault } \\
\text { Location }(\mathrm{km})\end{array}$ & $\begin{array}{c}\text { Estimated } \\
\text { Location }(\mathrm{km})\end{array}$ & $\begin{array}{c}\text { Error } \\
(\%)\end{array}$ & $\begin{array}{l}\text { Detection } \\
\text { Time }(\mathrm{ms})\end{array}$ \\
\hline B1-G & B1C1-G & 10 & 20 & 9 & 8.926 & 0.074 & 0.05 \\
\hline B1-G & B1C1-G & 10 & 20 & 15 & 15.085 & 0.085 & 0.03 \\
\hline B1-G & $\mathrm{B} 1 \mathrm{C} 1-\mathrm{G}$ & 10 & 20 & 28 & 27.068 & 0.068 & 0.01 \\
\hline B1-G & B1C1-G & 10 & 20 & 36 & 35.891 & 0.009 & 0.01 \\
\hline B1-G & $\mathrm{B} 1 \mathrm{C} 1-\mathrm{G}$ & 10 & 20 & 44 & 44.104 & 0.104 & 0.02 \\
\hline B1-G & B1C1-G & 10 & 20 & 51 & 51.211 & 0.211 & 0.03 \\
\hline B1-G & B $1 C 1-G$ & 10 & 20 & 60 & 60.282 & 0.282 & 0.02 \\
\hline B1-G & B1C1-G & 10 & 20 & 67 & 66.135 & 0.135 & 0.01 \\
\hline B1-G & B $1 C 1-G$ & 10 & 20 & 73 & 72.823 & 0.177 & 0.06 \\
\hline B1-G & $\mathrm{B} 1 \mathrm{C} 1-\mathrm{G}$ & 10 & 20 & 82 & 82.292 & 0.292 & 0.03 \\
\hline B1-G & B $1 C 1-G$ & 10 & 20 & 89 & 89.124 & 0.124 & 0.05 \\
\hline B1-G & $\mathrm{B} 1 \mathrm{C} 1-\mathrm{G}$ & 10 & 20 & 99 & 98.761 & 0.239 & 0.04 \\
\hline
\end{tabular}

\section{CONCLUSION}

This paper has outlined a new ANFIS method for locating evolving faults as well as shunt faults in the DCTPTL. System designing and simulations have performed in MATLAB software package for capturing samples of faulty signals by varying fault parameters. Low pass filter, sampler, and DFT have utilized to derive the features of raw current and voltage signals, which are further given as inputs for the fault locator. The proposed technique has overcome problems such as information from two ends of the transmission line and knowing the fault type. The simulation results showed that the method can be applied within the entire line and the accuracy of the fault location is high. Furthermore, the proposed method correctly located the evolving faults and tested with all fault events. Thus it can be applied for protection of real power systems as well.

\section{REFERENCES}

[1] Kang, N., Liao, Y. "Double-circuit transmission-line fault location utilizing synchronized current phasors." IEEE Transactions on Power Delivery. 28(2), 1040-1047, 2013

[2] Makmur, S., A. A. Mohd, Z., Mustafa, M., Sultan, A., Rusdi, N. "Algorithm for Fault Location and Classification on Parallel Transmission Line using Wavelet based on Clarke's Transformation."International Journal of Electrical and Computer Engineering. 8(2), 699-710, 2018.

[3] Hadi Bin Mustapha, A., Hamdan, R.,. Mohd Noh, F.,. Zambri, N.,. Jalil, M., Morsin, M., Basar, M. "Fault location identification of double circuit transmission line using discrete wavelet transform." Indonesian Journal of Electrical Engineering and Computer Science. 15(3), 1356-1365, 2019.

[4] Elkalashy, N., Kawady, T., Khater, W., Taalab, A. "Unsynchronized fault-location technique for double-circuit transmission systems independent of line parameters." IEEE Transactions on Power Delivery. 31(4), 1591-1600, 2016.

[5] Apostolopoulos, C., Korres, G. "A novel fault-location algorithm for double-circuit transmission lines without utilizing line parameters." IEEE Transactions on Power Delivery. 26(3), 1467-1478, 2011.

[6] Naresh, A., Sanjay, Ch., Chakravarthy, M. "Mamdani fuzzy expert system based directional relaying approach for six-phase transmission line." International Journal of Interactive Multimedia and Artificial Intelligence, 6(1) 41-50, 2020.

[7] Naresh kumar, A., Sanjay, Ch., Chakravarthy, M. "Fuzzy inference system-based solution to locate the crosscountry faults in parallel transmission line." The International Journal of Electrical Engineering \& Education. 2019. https://doi.org/10.1177/0020720919830905

[8] Naresh kumar, A., Sanjay, Ch., Chakravarthy, M. "A single-end directional relaying scheme for double-circuit transmission line using fuzzy expert system."Complex Intell. Syst. 2020. https://doi.org/10.1007/s40747-020-00131-w.

[9] Aleena, S., Anamika, Y. "Directional relaying using support vector machine for double circuit transmission lines including cross-country and inter-circuit faults." International Journal of Electrical Power \& Energy Systems. 81, 254-264, 2016

[10] Anamika, J., Thoke, A., Patel, R., Pawan, K. "Classification and location of single line to ground faults in double circuit transmission lines using artificial neural networks." International Journal Power and Energy Conversion. 12(2), 109-125, 2010.

[11] Aleena, S., Anamika, Y. "A novel single ended fault location scheme for parallel transmission lines using k-nearest neighbor algorithm." Computers and Electrical Engineering. 69, 41-53, 2018.

[12] Ahmad, A., Lufti Othman, M., Khudsiya Bibi Zainab, K., Hizam, H. "Adaptive ANN based differential protective relay for reliable power transformer protection operation during energisation." IAES International Journal of Artificial Intelligence. 8(4), 307-316, 2019.

[13] Wahiba, Y., Evgueniy, E. "Adaptive neuro-fuzzy inference system modelling for performance prediction of solar thermal energy system." Renewable Energy, 86, 302-315, 2016. 
[14] Javad, S., Hamid, A. "A new and accurate fault location algorithm for combined transmission lines using adaptive network-based fuzzy inference system.” Electric Power Systems Research. 79, 1538-1545, 2009.

[15] Reddy, J., Mohanta, D. "A wavelet-neuro-fuzzy combined approach for digital relaying of transmission line faults." Electric Power Compon Syst. 35(12):1385-40, 2007.

[16] Reddy, J., Mohanta, D. Adaptive neuro fuzzy inference system approach for transmission line fault classification and location incorporating effects of power swings." IET Gener. Transm. Distrib. 2(2), 235-244, 2008.

[17] Reddy, J., Mohanta, D. "Performance evaluation of an adaptive-network-based fuzzy inference system approach for location of faults on transmission lines using monte carlo simulation." IEEE Trans. Fuzzy Syst. 16(4), 909-919, 2008.

[18] Makwana, V.H., Bhalja, B.R. "New adaptive digital distance relaying scheme for double infeed parallel transmission line during inter circuit faults.” IET Gen. Trans. Dist. 5, 667-673, 2011.

[19] Mohagheghi, E., Bagherian, A., Ashiru, W.A., Esmaeilian, A. "A new fault location method based on adaptive neuro fuzzy in presence of SSSC on transmission line." International Conference on Environment and Electrical Engineering. Venice, Italy, 2012.

[20] Naresh kumar, A., Sanjay, Ch., Chakravarthy, M. "Adaptive neuro fuzzy inference system-based fault location technique in double circuit transmission line against simultaneous faults." Multiscale and Multidiscip. Model. Exp. and Des.2019. https://doi.org/10.1007/s41939-019-00066-x.

[21] Su, B., Dong, X., Sun, Y. "Impact of evolving fault on fault phase selector based on differential superimposed phase currents." In: IEEE Power Engineering Society General Meeting. Canada, 2004.

[22] Saurabh, K., Surya, S. "Time-domain algorithm for locating evolving faults." IEEE Transactions on Smart Grid. 3(4), 1584-1593, 2012.

[23] Xiangqing, J., Yuan, L. "Accurate location of evolving faults on transmission lines using sparse wide area measurements." International Journal of Emerging Electric Power Systems. 19(1), 2018.

[24] Guangbin, Z., Hongchun, S., Yuan, L. "An approach for detecting and locating evolving faults on transmission lines based on transient traveling waves." Electric Power Components and Systems. 45(2), 2017.

[25] Swetapadma, A., Yadav, A. "All shunt fault location including cross-country and evolving faults in transmission lines without fault type classification.” Electric Power Systems Research. 123, 1-12, 2015.

[26] Naresh, A., Chakravarthy, M. "Fuzzy inference system based distance estimation approach for multi location and transforming phase to ground faults in six phase transmission line." International Journal of Computational Intelligence Systems. 11(1), 757-769, 2018.

[27] Xiangqing, J., Yuan, L. "An analytical approach to locate evolving faults on transmission lines based on sparse wide area measurements." In: IEEE Power and Energy Conference. Illinois, Champaign, USA.2017. 